\title{
EDITORIAL
}

\section{Reforma educativa y cambio social}

Se ha dicho, y creemos que con bastante realismo, que todo sistema educativo suele ser, en mayor o menor grado, fiel reflejo del sistema social general y va siempre detrás. En este sentido, es preciso reconocer que resulta muy difícil promover el cambio des. de la educación. Sin embargo, es evidente que todo sistema educa. tivo, aunque esté influido o condicionado por el sistema social vigente, puede ser un importante factor de cambio en la medida que logre influir en la estratificación social y crear actitudes favo. rables al mismo cambio. En realidad, no lo olvidemos, el agente de cambio es el hombre o los hombres capacitados. Pero esta capacitación supone la opción por parte de la sociedad de un sistema educativo u otro, que siempre se apoya, a su vez, en una politica educativa determimada.

Desde este punto de vista, y conscientes de la dificultad intrínseca que supone valorar cualquier sistema educativo como instrun mento de cambio, queremos hacer unas reflexiones de conjunto sobre la actual reforma educativa. Algo así como tratar de responder a este interrogante que está planteado implicitamente en los comentarios a la nueva Ley de Educación: ¿El sistema educativo que se está implantando es pura Imagen del sistema social que trata de conservar 0 , más bien, contlene elementos capaces de transformar nuestra estructura social vigente?

Con el fin de sistematizar nuestras reflexiones, nos hemos preguntado cuáles son las condiciones principales para que una política educativa determinada sea un verdadero estímulo o factor de cambio social. Creemos que ha de contar con las cuatro características fundamentales que ponemos de relieve a continuación.

\section{PRIMERA: CLARIDAD DE OBJETIVOS \ SU ACEPTACION}

Si se admite que la educación es una preparación para la vida real y tiene una utillidad para ol individuo y para la sociedad, lo 
primero que hay que preguntarse es qué tipo de hombre se busca formar y para qué tipo de sociedad. En una sociedad establey, sobra* rá tal planteamiento inicial. En una sociedad en cambio y transtor. mación - o cue se dice pretender la transformación y el desarrollo- solamente si se fijan con claridad los fines y los objetivos del sistema educativo podrán establecerse los métodos pedagón gicos adectuados para el logro de esos objetivos.

Un sistema educativo se puede proponer, por ejemplo: al Fol. mar el espíritu para un comportamiento de los alumnos que esté de acuerdo con una escala de valores determinada o, principalmen. te. transmitir una herencia cultural y una serie de conocimientos más o menos abstractos; b) asimismo puede buscar preparar a los jóvenes para una educación permanente que nunca termina 0 , por el contrario, contentarse con seleccionar los alumnos para una función pública o para desarrollar determinadas actividades pro. fesionales.

Normalmente, cualquier sistema educativo se suele proponer como meta una mezcla de estos y otros objetivos. Una prueba de esto la tenemos en el art. $1 x^{\circ}$ de la Ley de Educación cuando señala como fines: La formación humana integral, el desarrollo armónico de la personalidad y la preparación para el ejercicio responsable de la libertad, la integración y promoción social, etc.

La verdad es que cuesta trabajo vislumbrar el tipo de hombre que la Ley quiere formar. Nos referimos a que no queda clara en el art. $1^{\circ}$ de la Ley la opción que tiene que hacer todo sistema educativo atendiendo a los comportamientos; es decir, si se quiere formar hombres uobedientes", sumisos 0 , más bien, autónomos, individuales, innovadores, etc.

Por más que en el apartado 2 de este artículo se señale como uno de los objetivos «la adquisición de hábitos de estudio y de trabajo", también dice que los objetivos antes indicados tienen que inspirarse "en la tradición y cultura patrias", y finalmente, se añade que "todo ello (todos los objetivos) de conformidad con lo establecido en los Principios del Movimiento Nacional y demás Leyes Fundamentales del Reino". Todo esto es lógico, pues una ley ordinaria tiene que estar de acuerdo con las Leyes fundamentales, pero es revelador del tipo de hombre que se pretende formar y de la escala de valores, creencias y conocimientos que se busca transmitir a los alumnos. Son los de la actual sociedad; lo cual podría ser una de las causas que explicaran la actual situación anómala de la Universidad. Desde el punto de vista, pues, de los objetivos, el nuevo sistema educativo parece es eminentemente conservador.

Sin embargo, desde otro punto de vista, como es el de los nuevos métodos pedagógicos (arts. $27,18,11$ ) que se pretende 
aplicar y que tienden a despertar en el alumno la iniciativa, originalidad y lla aptitud creadora, habría que decir que, pedagógica mente al menos, el nuevo sistena busca crear actitudes favorables al cambio social.

\section{SEGUNDA: COHEPENCIA CON UNA POLTICA SOCHAL MAS AMPLIA}

Es cierto que un sistema educativo puede wavorecer el cambio en la medida en que sea coherente con la totalidad de los cambios sociales y contribuye a sdirigirlosm como parte de una politica general, mediante una acción intensa sobre las generacioes jóvenes, para que los cambios que efectivamente se producen adquieran estabullidad.

Alguien ha enjuiciado, creemos gue apresuradamente y sin demostrarlo, la reforma educativa española, sil tho como un tapón, sí como una especie de sustitutivo de las reformas sociales que quedan por hacer. Dejando de lado el análisis más extenso de este juicio de valor, que nos llevaria lejos, to que sí parece un contra. sentido es pretender fomentar en la clase, en el colegio o en la Universidad actitudes y comportamientos de gran libertad, de iniciativa, de creatividad y mayor participación activa, mientras que en la empresa, por ejemplo, y en la sociedad en general, aparezca lo contrario.

Establecer como uno de los objetivos el hacer partícipe de la educación a toda la población española, puede significhar mucho y puede querer decix simplemente escolarizar a todos los niños no escolarizados o mal escolarizados. Quedarse aquí sería tanto como tratar de corregirla Fijar, como lo hace la Ley de Educación, la oblingatoriedad y gratuidad (art. 2, 2) de la educación general hásica y la formación profesional de primer grado, en una primera lase, y la extensión de la gratuidad, en una segunda tase, al Bachillerato es sentar las bases para una mayor homogeneización de la sociedad, estableciendo un consenso cultural previs a cualquier especificidad profesional. En este sentido, puede ser la reforma educativa un factor de cambio social.

Con todo, sería un error creer que puede obtenerse una abso. luta igualdad de oportunidades frente a la enseñanza por medios puramente económicos (gratuidad), como parece desprenderse del nuevo sistema. Esto equivaldría a ignorar el intlujo que las desigualdades de origen familiar tienen en los hijos. Aunque la enseñanza media y universitaria lleguen a ser gratulus, suponen cieríos gastos que no están al alcance de las familias modestas. $V$, sobre todo, las peores condiciones de alimentación, alojamiento, etcétera, repercuten en el rendimiento escolar. 
Esto quiere decir que un sistema educativo tal como el nuestro sólo podrá estimular y preparar para el cambio en la medida en que una politica social general aborde las reformas sociales capa ces de implantar una más Justa distribución de la renta y del poder social. En el contexto de la sociedad actual parece claro que tales premisas no se cumplen.

\section{TERCERA: PERSPECTVA DEL FUTURO}

La educación puede y debe cumplir uma función de servicio social Importante ("servicio públicon, dice la Ley) en cuanto que ofrece a todos los individuos la posibilidad de adquirir una cultura fundamental. La educación puede constitulir, además, un factor de la evolución social. Finalmente, a la educación se la considera hoy también como una especie de Industria productora y suminis. tradora de les cualificachones que necesita una sociedad moderna en transformación constante.

Esto exige que entre los objetivos a largo plazo de un sistema educativo aparezca bien definida la imagen de sociedad que se pretende comitgurar. $Y$ a partir de ahí es preciso planificar la ensenanza, conscientes de que la programación educativa debe formar parte de una politica más de conjunto, como pueden ser los planes de desarrollo económico y social.

Oueda indicado ya cómo en el ark. $10^{\circ}$ de la ley de Educación se prezende crear un tipo de hombre con una escala de valores determinada. Pero también creemos que se intenta configurar un cierto tipo de sociedad condicionada en su evolución por thos principios normativos básicos muy concretos. No obstante, el nuevo sistema educativo se propone, como un objetivo más, el capacitar a los alumnos en orden a una tarea útill para la sociedad" y con miras al rejercicio de actividades profesionales que permitan impulsar y acrecentar el desarrollo social, cuitural, cientifico y económico del país".

Una auténtica planificación de la educación-todavía estamos

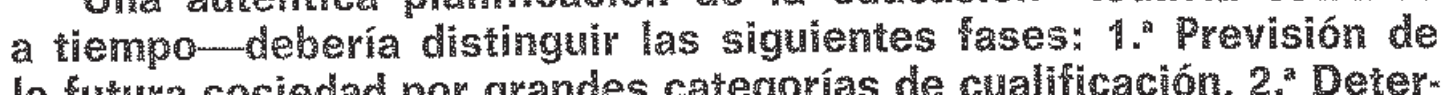
la futura sociedad por grandes categorias de cualificación. $2{ }^{2}$ Deter minación de los programas precisos para impartir aquellas cualifi-

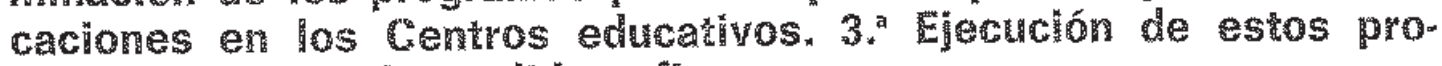
gramas a través de medidas eficaces.

Valorada con esta óptica, en su conjunto, la actual política edu. cativa da la impresión de que se apoya demasiado en previsiones cuantitativas: escolaridad para todos los españoles, gratuidad igual. mente para lodos. enseñanza secundaria y superior para el mayor número posible, y bastante menos en previsiones cualitativas. ¿Qué 
necesidades concretas, qué demanda de puestos cuallificados por especialidades será la de la sociedad de los años ochenta? Sin duda, en este punto, la reforma educativa se ve condiclonada por esa falta de planificación del empleo en el III Plan de Desarrollo, que en el número anterior de esta misma Pevista pusimos de relieve.

\section{CUARTA: REMOCION DE LOS OBSTACULOS QUE FRENAN EL CAMBIO}

En la exposición de motivos de la Ley de Educación, se reconoce abiertamente que las distintas retormas parciales educativas han ido siempre a la zaga de la presión socilal. Apoyándose en esta realidad, la ley opta por una reforma de todo el süstema educativo, y en su implantación estamos ya embarcados. Los trenos a esta reforma pueden provenir, como en todos los países, principalmente de los cuatro grupos más intereseados: el propio Estado, los profe. sores, los estudiantes con sus familias y quienes se benefician de la educación, como pueden ser las empresas que necesitan personal cualificado y la misma Administración, que precisa de buenos funchonarios.

Ya hemos señalado que todo sistema educativo astá ligado a un cierto tipo de sociedad, con sus valores. Yuna reforma educa. tiva, quizá más que otras, suppone hacer una kopción politican tun. damental y a largo plazo. Precisamente por eso, los goblemos. transitorios por definición, no se suelen comprometer en configurar el tipo de sociedad más apropiado a largo plazo. Por otra narte, toda reforma educativa es una reforma costosa y hay zuse anbitran los recursos recortando otros capítulos del presupuesto del Estato o inerementando los ingresos de la Hacienda Püblica, lo que supone una mayor presión fiscal. Todo lo cual puede exphicar que el mismo Estado no se atreva, a veces, a enfrentarse con todas las consecuencias que lleva consigo una reforma educativa a largo plazo.

$Y$ por lo que respecta a los profesores, éstos temen, a menudo, perder su función de árbitros o jueces con la mplantación de los nuevas métodos de enseñanza y por la modtucación de las rela ciones profesor-alumno, lo que hace que puedan obstaculizar también el cambio de sistema educativo.

Además, dadas las características de la enseñanza secundarta en España, en la que juega un papel importante la enseñanza no estatal, los padres de los alumnos pueden oponer incluso resistencia a la actual reforma educativa. Intereses de clase social que se resisten a una mayor homogeneización e integración social de los alumnos en los Centros educativos, sin discriminaciones de origen familiar o de nivel social de los padres de los mismos. 
Finalmente, pueden constituir un obstáculo al cambio de sistema educativo quienes en realidad se benefician de la educación, como pueden ser las diversas empresas y la propia Administra. ción. Por una parte, piensan que el Estado debe proporcionarles buenos técnicos, hombres competentes, y por otra, no aceptan muchas veces la ldea de que la educación forma parte de sus pro. pias responsabilldades.

Esta breve exposición de las resistencias a la retorma educan tiva $y$, en detinitiva, al cambio social es incompleta. Existen ouras. Unicamente hemos indicado algunas para poner de relieve que la Ley de Educación, la aplicación reglamentaria de la misma, puede tropezar con obstáculos diffoiles de salvar. lo importante es pre verlos y adoptar las medidas efficaces para superarlos, con una mayor flexibilidad en la aplicación de la Ley y responsabulizando eficazmente a todos los afectados, desde el sujeto pasivo. los alumnos, hasta el suieto activo, los profesores, pasando por los titulares de los Centros de enseñanza y los directivos de la po litica educativa.

Ahora bien, para llegar a consegulr esto es preciso zener conciencia clara de la inevitabilidad de los cambios sociales, pues, como ha dicho acertadamente el Jefe de la Secretaria Técnica del Ministro Comisario del Plan de Desarrollo, D. Emillo Sánchez Pin. tado, "la opción que se nos presenta no es, por tanto, entre inmovilldad o cambio social, sino entre cambio planificado y orientado hacia fines libre y racionalmente aceptados por la comunidad o la transformacion irresponsable, imprevista y muchas veces convulsi. va del cuerpo social" (cfr. "Desarrollon, 25 de jumio de 1972). 